\title{
Isolation and Characterization of Desulfitobacterium frappieri sp. nov., an Anaerobic Bacterium Which Reductively Dechlorinates Pentachlorophenol to 3-Chlorophenol
}

\author{
B. BOUCHARD, R. BEAUDET, ${ }^{*}$ R. VILLEMUR, G. MCSWEEN, F. LÉPINE, AND J.-G. BISAILLON \\ Centre de Recherche en Microbiologie Appliquée, Institut Armand-Frappier, \\ Université du Québec, Laval, Québec, Canada H7N $4 Z 3$
}

\begin{abstract}
An anaerobic bacterium, strain PCP-1 ${ }^{\mathrm{T}}(\mathrm{T}=$ type strain), which dechlorinates pentachlorophenol $(\mathrm{PCP})$ to 3-chlorophenol, was isolated from a methanogenic consortium. This organism is a spore-forming rod-shaped bacterium that is nonmotile, asaccharolytic, and Gram stain negative but Gram type positive as determined by electron microscopic observations. Inorganic electron acceptors, such as sulfite, thiosulfate, and nitrate (but not sulfate), stimulate growth in the presence of pyruvate and yeast extract. The optimum pH and optimum temperature for growth are 7.5 and $38^{\circ} \mathrm{C}$, respectively. The dechlorination pathway is: $\mathrm{PCP} \rightarrow 2,3,4,5$-tetrachlorophenol $\rightarrow$ 3,4,5-trichlorophenol $\rightarrow$ 3,5-dichlorophenol $\rightarrow$ 3-chlorophenol. This bacterium dechlorinates several different chlorophenols at ortho, meta, and para positions; exceptions to this are 2,3-dichlorophenol, 2,5dichlorophenol, 3,4-dichlorophenol, and the monochlorophenols. The time course of PCP dechlorination suggests that two enzyme systems are involved in dehalogenation in strain PCP-1 ${ }^{\mathbf{T}}$. One system is inducible for ortho dechlorination, and the second system is inducible for meta and para dechlorinations. A 16S rRNA analysis revealed that strain PCP-1 ${ }^{\mathrm{T}}$ exhibits $95 \%$ homology with Desulfitobacterium dehalogenans JW/IU-DC1, an anaerobic bacterium which can dehalogenate chlorophenols only in ortho positions. These results suggest that strain PCP-1 ${ }^{\mathrm{T}}$ is a member of a new species and belongs to the recently proposed genus Desulfitobacterium. Strain PCP-1 ${ }^{\mathrm{T}}$ differs from $D$. dehalogenans JW/IU-DC1 by its broader range of chlorophenol dechlorination. Strain PCP-1 is the type strain of the new species, Desulfitobacterium frappieri.
\end{abstract}

Only a few anaerobic bacteria that can reductively dechlorinate chlorophenols have been isolated in pure culture. $D e$ sulfomonile tiedjei DCB-1 is the best-described dechlorinating anaerobic bacterium to date (7). This organism is a strictly anaerobic, gram-negative, sulfate-reducing bacterium that obtains energy for growth from reductive dehalogenation of 3 -chlorobenzoate with formate as an electron donor $(8,19)$. In the presence of 3-chlorobenzoate, this strain can also dechlorinate meta-substituted halobenzoates $(9,15)$ and chlorophenols (18). Madsen and Licht (16) isolated a Clostridium-like microorganism, strain DCB-2, that can dechlorinate 2,4,6-chlorophenol to 2,4-chlorophenol and finally to 4-chlorophenol; removal of meta-substituted chlorine has been observed only with 3,5-chlorophenol. Desulfitobacterium dehalogenans JW/ IU-DC1, a gram-positive anaerobic bacterium, can dehalogenate a wide range of chlorophenols, including pentachlorophenol (PCP) and related compounds, at the ortho position (22, 23 ). This strain can use various alternative electron acceptors, including sulfur, sulfoxy anions (except sulfate), nitrate, and fumarate. Recently, a novel, gram-negative, facultatively anaerobic, rod-shaped bacterium which can grow anaerobically via reductive dehalogenation of 2-chlorophenol was isolated (5). This microaerophilic bacterium is a member of the delta subclass of the class Proteobacteria and is more closely related to the myxobacteria than to the sulfidogenic bacteria.

A methanogenic consortium that degraded PCP completely in medium containing glucose and formate as complementary carbon sources was enriched in our laboratory. This consortium dechlorinated PCP to phenol, which was then mineralized (12). Spore-forming bacteria were involved in the dechlorina-

* Corresponding author. Mailing address: Centre de Recherche en Microbiologie Appliquée, Institut Armand-Frappier, Université du Québec, C.P. 100, Laval, Québec, Canada H7N 4Z3. tion of PCP to 3-chlorophenol (3-CP), and a syntrophic bacterium was responsible for the dechlorination of 3-CP (11). In this paper, we describe the isolation and characterization of anaerobic bacterial strain PCP-1 ${ }^{\mathrm{T}}(\mathrm{T}=$ type strain), which was responsible for dechlorination of $\mathrm{PCP}$ to $3-\mathrm{CP}$ in this consortium. Strain PCP-1 ${ }^{\mathrm{T}}$ is the only known anaerobic bacterium that is able to dechlorinate chlorophenols in ortho, meta, and para positions.

\section{MATERIALS AND METHODS}

Origin and cultivation of the PCP-dechlorinating consortium. The anaerobic consortium that dechlorinated PCP was obtained from a mixture of anaerobic sewage sludge and soil samples that had been contaminated with PCP (12). This consortium was maintained with agitation at $29^{\circ} \mathrm{C}$ in a 2 -liter continuous-flow sludge reactor that was fed with mineral salt medium containing $35 \mu \mathrm{M} \mathrm{PCP \text {, }}$ $0.5 \mathrm{~g}$ of glucose per liter, and $1.1 \mathrm{~g}$ of sodium formate per liter $(11,12)$. This reactor was operated at a hydraulic retention time of 10 days. Under these conditions, the microorganisms in the reactor were free and not associated in granules.

Enrichment and isolation of the PCP-dechlorinating microorganism. Samples from the continuous-flow reactor were transferred into $70-\mathrm{ml}$ serum bottles and incubated in a water bath at $80^{\circ} \mathrm{C}$ for $30 \mathrm{~min}$. Then the cultures were incubated at $29^{\circ} \mathrm{C}$, and PCP ( $3 \mathrm{mg} / \mathrm{liter}$ ) was added $24 \mathrm{~h}$ later. The dechlorinating cultures were transferred periodically by using $10 \%$ (vol/vol) inocula into $70-\mathrm{ml}$ serum bottles containing $25 \mathrm{ml}$ of medium $\mathrm{A}$. This medium was prepared as described previously $(11,12)$. It was composed of the minimal medium described by Boyd et al. (2) supplemented with 3 to $5 \mathrm{mg}$ of PCP per liter, $1 \mathrm{~g}$ of glucose per liter, $2.26 \mathrm{~g}$ of sodium formate per liter, and $2 \%$ (vol/vol) adsorbent DEAE-Sephacel beads (Pharmacia Biotech). The DEAE-Sephacel was washed three times in mineral salt medium, sparged with $\mathrm{N}_{2}-\mathrm{H}_{2}-\mathrm{CO}_{2}(80: 10: 10)$, and autoclaved for 15 min. After several months of enrichment in serum bottles, an aliquot was diluted serially in fresh medium, and $0.1 \mathrm{ml}$ was inoculated onto Columbia agar medium ANA 1121 (Laboratoires Quelab, Montreal, Canada) that had been prereduced in an anaerobic jar (BBL GasPak system) for $48 \mathrm{~h}$. The microbiological work was performed in an anaerobic chamber (Bactron II: Sheldon Manufacturing, Inc., Cornelius, Oreg.) under a gas mixture containing $80 \% \mathrm{~N}_{2}, 10 \% \mathrm{H}_{2}$, and $10 \%$ $\mathrm{CO}_{2}$. After 10 to 15 days of incubation at $29^{\circ} \mathrm{C}$ under anaerobic conditions, several colonies were isolated; these colonies were resuspended in $2 \mathrm{ml}$ of mineral salt medium and inoculated into medium A supplemented with $0.1 \%$ (wt/vol) yeast extract in a serum bottle. The resulting cultures were incubated at $29^{\circ} \mathrm{C}$ and were tested for PCP-dechlorinating activity. Some isolates were able to 
dechlorinate PCP to 3-CP. One of the strains isolated was purified by subcul turing it on Columbia solid medium. The purity of this culture was checked by photonic microscopy after Gram staining and by examining the colonies on solid medium.

Culture conditions and characterization of PCP-1 ${ }^{\mathrm{T}}$. Whether strain PCP-1 ${ }^{\mathrm{T}}$ could grow with different organic substrates or vitamins was determined by adding the following compounds to mineral salt medium containing $2 \%$ (vol/vol) DEAE-Sephacel beads: 20 and $55 \mathrm{mM}$ pyruvate, 0.02 and $0.1 \%$ (wt/vol) yeast extract, $100 \mu \mathrm{g}$ of hemin per liter, and $200 \mu \mathrm{g}$ of 1,4-naphthoquinone per liter. Some biochemical properties of PCP- $1^{\mathrm{T}}$ were determined by using the anaerobic API 20E system (Bio-Mérieux, Montreal, Canada). Different electron acceptors were tested by adding $10 \mathrm{mM} \mathrm{Na} \mathrm{SO}_{4}, 5 \mathrm{mM} \mathrm{Na}_{2} \mathrm{SO}_{3}, 10 \mathrm{mM} \mathrm{Na}{ }_{2} \mathrm{~S}_{2} \mathrm{O}_{3}$, or 10 $\mathrm{mM} \mathrm{KNO}_{3}$ to culture medium containing $55 \mathrm{mM}$ pyruvate, $0.02 \%$ yeast extract and $2 \%$ DEAE-Sephacel beads. In this experiment, cysteine- $\mathrm{HCl}(2 \mathrm{mM})$ was used as the reducing agent instead of $\mathrm{Na}_{2} \mathrm{~S}$.

$\mathrm{pH}$ and temperature ranges for growth. The $\mathrm{pH}$ and temperature ranges for growth of strain PCP- $1^{\mathrm{T}}$ were determined by monitoring the increase in optical density at $660 \mathrm{~nm}$ in culture medium containing $55 \mathrm{mM}$ pyruvate, $0.1 \%$ yeast extract, and $5 \mathrm{mM} \mathrm{Na}_{2} \mathrm{SO}_{3}$. Media having $\mathrm{pH}$ values ranging from 6.0 to 9.0 were prepared by varying the acid and base components of the buffer. The $\mathrm{pH}$ was kept constant by frequently adjusting it with sterile $2 \mathrm{~N} \mathrm{NaOH}$. The $\mathrm{pH}$ range for growth was determined at $37^{\circ} \mathrm{C}$. The temperature range for growth was determined in $\mathrm{pH} 7.2$ culture medium incubated at $15,20,29,37,40$, and $45^{\circ} \mathrm{C}$. Assays were performed in duplicate.

Sensitivity to oxygen. The sensitivity of bacterial growth and dechlorination of 2,4,6-trichlorophenol to oxygen was determined in 120 - $\mathrm{ml}$ serum bottles containing $20 \mathrm{ml}$ of culture medium which contained no reducing solution. The medium was prepared under a gas mixture containing $80 \% \mathrm{~N}_{2}, 10 \% \mathrm{H}_{2}$ and $10 \% \mathrm{CO}_{2}$. A volume of air corresponding to $0,1,2,5$, and $10 \%$ of the headspace volume was added to the gas mixture. Each bottle was inoculated with $1.0 \mathrm{ml}$ of a PCP-1 ${ }^{\mathrm{T}}$ culture in the exponential growth phase. The bottles were incubated in a shaking incubator at $37^{\circ} \mathrm{C}$ for 8 days.

Analytical procedure. The different chlorophenols were analyzed routinely by high-pressure liquid chromatography (HPLC), using a reverse-phase NovaPak $\mathrm{C}_{18}$ column ( 3.9 by $150 \mathrm{~mm}$ ). The Waters system used comprised a model 510 pump connected to a model 481 Lambda-Max Lc spectrophotometer and a model Professional 350 Digital computer. Some chlorophenol degradation in termediates were identified with a gas chromatograph (Varian model 3500) connected to a mass spectrometer (Ion trap 800; Finnigan Mat). The HPLC and gas chromatography-mass spectrometry operating parameters used have been described previously $(11,12)$.

Electron microscopy. The morphology of PCP $-1^{\mathbf{T}}$ was determined with a Hitachi model 7100 electron microscope after negative staining with $1 \%$ phos photungstate as described by Alain et al. (1). Ultrathin sections were also prepared Bacteria were fixed by incubating them for $15 \mathrm{~min}$ at room temperature with $2.5 \%$ (vol/vol) glutataldehyde in $0.05 \mathrm{M}$ cacodylate buffer ( $\mathrm{pH} 7.2$ ). The cells were pelleted by centrifugation in an Eppendorf tube at 1,300 rpm $(15,000 \times g)$ for 3 min and washed three times with a $3 \%(\mathrm{wt} / \mathrm{vol})$ sucrose solution in cacodylate buffer. The cell pellets were then postfixed with $2 \%$ (wt/vol) osmium tetroxide dehydrated in acetone, and embedded in Spurr resin. Ultrathin sections were stained with $5 \%$ (wt/vol) uranyl acetate for $20 \mathrm{~min}$ and then with lead citrate for $5 \mathrm{~min}$ before they were examined.

Determination of $\mathbf{G}+\mathbf{C}$ content. The guanine-plus-cytosine $(\mathrm{G}+\mathrm{C})$ content was determined after enzymatic digestions with nuclease $\mathrm{P} 1$ and alkaline phosphatase and HPLC separation of nucleosides as described by Mesbah et al. (17).

DNA manipulation. Extraction of total PCP-1 ${ }^{\mathrm{T}}$ DNA, PCR amplification of the $16 \mathrm{~S}$ ribosomal gene, cloning and sequencing of the gene, and a sequence analysis were performed as described by Li et al. (14). Briefly, the $16 \mathrm{~S}$ ribosomal gene was amplified by PCR by using universal eubacterial primers (4) and strain PCP- $1^{\mathrm{T}}$ genomic DNA. The resulting $1.6-\mathrm{kbp}$ DNA fragment was then cloned in the Bluescript vector (Stratagene) and sequenced by the dideoxynucleotide method (21). The PCP-1 ${ }^{\mathrm{T}}$ sequence was compared with sequences obtained from databases by using the FASTA and BLAST programs. Phylogenetic analyses were performed by using different programs of the PHYLIP package (version 3.5) (10) and the most closely related species (see Table 1 and Fig. 5). The secondary structure of minimum free energy for an RNA molecule based on previously published values for stacking and loop-destabilizing energies was calculated by using the FOLD program (25) of the GCG sequence analysis package (Genetics Computer Group, Inc.)

Dechlorination of different chlorophenols. Experiments to determine whether various chlorophenols were dechlorinated were performed in serum bottles containing $25 \mathrm{ml}$ of mineral salt medium supplemented with $20 \mathrm{mM}$ pyruvate, $0.02 \%$ (wt/vol) yeast extract, and $2 \%$ (vol/vol) DEAE-Sephacel; $2.5 \mathrm{ml}$ of an active culture was used as the inoculum in each experiment. The chlorophenols were added $24 \mathrm{~h}$ after inoculation at concentrations of $5 \mathrm{mg} /$ liter $(21 \mu \mathrm{M})$ for the tetrachlorophenols and $3 \mathrm{mg} /$ liter $(16$ to $23 \mu \mathrm{M})$ for the other chlorophenols. In some experiments, $3 \mathrm{mg}$ of PCP per liter $(11 \mu \mathrm{M})$ was also added to the culture to induce dechlorinating activity. The cultures were incubated at $29^{\circ} \mathrm{C}$. Triplicate preparations were analyzed by HPLC at zero time and on days $1,2,4$, and 8 .

Nucleotide sequence accession number. The GenBank accession number for the $16 \mathrm{~S}$ rRNA sequence of Desulfitobacterium frappieri $\mathrm{PCP}_{-1}{ }^{\mathbf{T}}$ is $\mathrm{U} 40078$.

\section{RESULTS}

Isolation and characterization of PCP-1 ${ }^{\mathrm{T}}$. PCP-dehalogenating strain $\mathrm{PCP}-1^{\mathrm{T}}$ was isolated after heat treatment and growth of enrichment cultures in serum bottles containing glucose, sodium formate and PCP. The strain was isolated by repeatedly preparing serial dilutions, inoculating preparations onto solid medium, and recovering the most dilute dechlorinating biomass. Strain PCP $-1^{\mathrm{T}}$ grew on anaerobic Columbia agar within 10 to 15 days when it was incubated at $29^{\circ} \mathrm{C}$. The colonies of this organism were white, circular and convex with undulate margins, and $2.5 \mathrm{~mm}$ in diameter. Electron micrographs revealed that strain PCP $-1^{\mathrm{T}}$ cells are rod shaped and 2.2 to $4.5 \mu \mathrm{m}$ long by $0.7 \mu \mathrm{m}$ wide (Fig. 1). No flagellum was observed. A terminal endospore was present in some cells. The Gram stain reaction was negative, regardless of the growth phase. However, no outer membrane was observed in electron micrographs, suggesting that PCP-1 ${ }^{\mathrm{T}}$ is Gram type positive (Fig. 1B). The $\mathrm{G}+\mathrm{C}$ content of the genomic DNA was $46 \%$ $\mathrm{mol} \%$.

The dechlorinating activities of isolated colonies were observed in liquid cultures only when $0.1 \%$ (wt/vol) yeast extract was added to medium $A$ or when $20 \mathrm{mM}$ pyruvate replaced glucose-formate as the secondary carbon source. As strain PCP $-1^{\mathrm{T}}$ could not grow on glucose and formate, it was necessary to have some other bacteria in the enrichment culture to transform these compounds into utilizable substrates. Pyruvate was the only defined organic substrate utilized in the presence of $0.02 \%$ yeast extract that provided carbon and energy to sustain fermentative growth of strain PCP $-1^{\mathrm{T}}$. DEAE-Sephacel beads were important during cultivation and acted as an adsorbent to reduce the toxicity of some components of the medium, such as $\mathrm{Na}_{2} \mathrm{~S}$ (data not shown). However, the beads were not necessary when the $\mathrm{Na}_{2} \mathrm{~S}$ concentration in the medium was reduced by a factor of 10 . A mixture of glucose and formate did not support growth. Hemin and 1,4-naphthoquinone were not necessary for growth and dechlorinating activity. The anaerobic API $20 \mathrm{E}$ system data showed that PCP-1 ${ }^{\mathrm{T}}$ was positive for indole formation; weakly positive for catalase activity; negative for hydrolysis of urea and esculin; negative for fermentation of glucose, mannitol, lactose, saccharose, maltose, salicin, xylose, arabinose, glycerol, cellobiose, mannose, melezitose, raffinose, sorbitol, rhamnose, and trehalose; and negative for gelatin liquefaction. Some other alternative electron acceptors, including sulfite, thiosulfite, and nitrate (but not sulfate) stimulated growth of PCP-1 ${ }^{\mathrm{T}}$ in the presence of pyruvate and yeast extract (Fig. 2), suggesting that PCP-1 ${ }^{\mathrm{T}}$ was able to reduce these inorganic substances. The $\mathrm{pH}$ range for growth of strain PCP-1 ${ }^{\mathrm{T}}$ was 6.0 to 9 , and the optimum $\mathrm{pH}$ was 7.5. The temperature range for growth was 15 to $45^{\circ} \mathrm{C}$, and the optimum temperature was around $38^{\circ} \mathrm{C}$. Growth and dechlorination did not occur when a serum bottle contained $1 \%$ air in the gas phase. The generation time of strain PCP-1 ${ }^{\mathrm{T}}$ in medium containing $20 \mathrm{mM}$ pyruvate, $0.02 \%$ yeast extract, and $5 \mathrm{mg}$ of PCP per liter at $\mathrm{pH} 7.2$ was approximately $3 \mathrm{~h}$ at $29^{\circ} \mathrm{C}$.

Phylogeny. The $16 \mathrm{~S}$ ribosomal gene of strain PCP $-1^{\mathrm{T}}$ was amplified by PCR and then cloned and sequenced. The $\mathrm{PCP}-1^{\mathrm{T}} 16 \mathrm{~S}$ rRNA gene is unusually long; this gene is 1,654 nucleotides long, which is about 100 nucleotides longer than most 16S rRNA genes. A search of the gene databases revealed that the $16 \mathrm{~S}$ rRNA gene of Desulfitobacterium dehalogenans is very similar (level of similarity, 95\%) to the $16 \mathrm{~S}$ rRNA sequence of strain PCP-1 ${ }^{\mathrm{T}}$. A 128 -nucleotide insertion (nucleotides 63 to 190) is the main difference between the two sequences and is also responsible of the unusual length of the PCP $-1^{\mathrm{T}} 16 \mathrm{~S}$ gene. This sequence is located in the secondary 

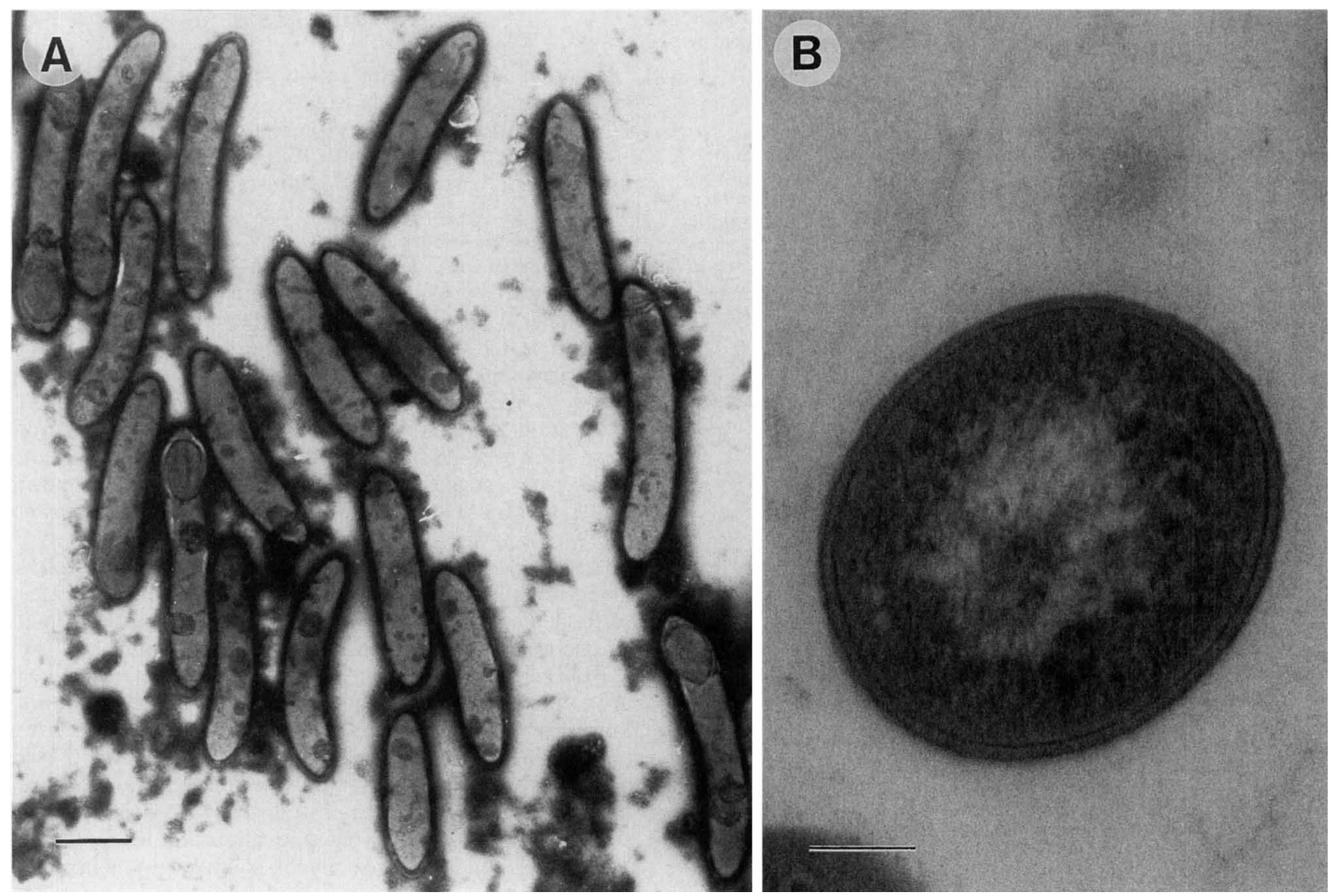
$1 \mu \mathrm{m}$.

structure of helix 6-VI (Escherichia coli nomenclature) (20) (Fig. 3). An analysis of the putative secondary structure of this region of the PCP- ${ }^{\mathrm{T}}$ 16S rRNA revealed a long loop with $72 \%$ base pairing. In Desulfitobacterium dehalogenans, a small loop similar in size to the $E$. coli loop was predicted.

A phylogenetic analysis was performed with related species (Table 1 and Fig. 4). The species used were chosen on the basis of the results of phylogenetic analyses performed by Utkin et

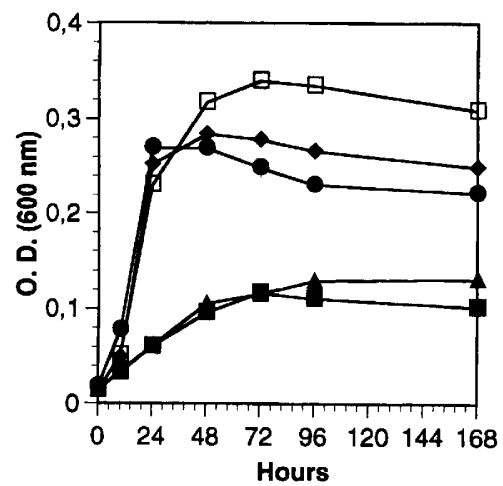

FIG. 2. Growth of strain PCP-1 $1^{\mathbf{T}}$ in medium containing $55 \mathrm{mM}$ pyruvate plus $0.1 \%$ (wt/vol) yeast extract $(\square)$ and in the same medium supplemented with the electron acceptors $10 \mathrm{mM}$ sulfate $(\Delta), 5 \mathrm{mM}$ sulfite $(\bullet), 10 \mathrm{mM}$ thiosulfate $(\square)$, and $10 \mathrm{mM}$ nitrate (). Data are means of duplicate determinations. O.D. (600 $\mathrm{nm}$ ), optical density at $600 \mathrm{~nm}$ al. (23) for Desulfitobacterium dehalogenans and by Collins et al. (6) for Clostridium and Clostridium-like species. The results of the phylogenetic analysis confirmed the close relationship between strain PCP $-1^{\mathrm{T}}$ and Desulfitobacterium dehalogenans. Desulfotomaculum orientis has been reported to have the $16 \mathrm{~S}$ rRNA sequence that is most similar to the Desulfitobacterium dehalogenans sequence (23) (level of similarity, 93.4\%), although more than $14 \%$ of the reported sequence is composed of undetermined or missing nucleotides. A comparison of the strain PCP-1 ${ }^{\mathrm{T}}$, Desulfitobacterium dehalogenans, and Desulfotomaculum orientis $16 \mathrm{~S}$ rRNA sequences revealed that strain PCP $-1^{\mathrm{T}}$ is more closely related to Desulfitobacterium dehalogenans (level of similarity, 96.8\%) than to Desulfotomaculum orientis (level of similarity, 92.3\%). These results suggest that strain $\mathrm{PCP}-1^{\mathrm{T}}$ belongs to the genus Desulfitobacterium. Strain PCP-1 is the type strain of a new species named Desulfitobacterium frappieri.

Description of Desulfitobacterium frappieri sp. nov. Desulfitobacterium frappieri (frap.pi.e'ri M. L. gen. n. frappieri, of Frappier, in honor of Armand Frappier, a renowned Canadian microbiologist). Strain PCP-1 is the type strain of Desulfitobacterium frappieri. This strain has been deposited in the American Type Culture Collection.

Dechlorinating activity. The kinetics of dechlorination of PCP to 3-CP is shown in Fig. 5. PCP was dechlorinated to 3,4,5-trichlorophenol in less than $12 \mathrm{~h}$. A lag of $36 \mathrm{~h}$ occurred before 3,4,5-trichlorophenol began to be dechlorinated to 3,5dichlorophenol and 3-CP. A trace amount of 3,4-dichlorophenol was also found, and this trace probably originated from 
E. coli

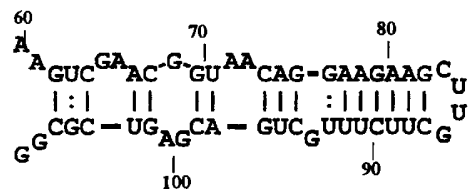

D. frappieri
D. dehalogenans

FIG. 3. Secondary structure of helix 6-VI of E. coli 16S rRNA (20) and the proposed helices of Desulfitobacterium dehalogenans and Desulfitobacterium frappieri. The $E$. coli numbering is the numbering of Brosius et al. (3). Canonical pairs are connected by vertical lines, and G-U pairs are connected by colons. nt, nucleotide.

2,3,4,6-tetrachlorophenol, a known contaminant of PCP preparations. We examined the dechlorination of all possible chlorophenols by strain PCP-1 ${ }^{\mathrm{T}}$ (Table 2). Dechlorinations in ortho, meta, and para positions were observed. The following chlorophenols were not dehalogenated: 2-chlorophenol, 3-CP, 4-chlorophenol, 2,5-dichlorophenol, and 3,4-dichlorophenol. No dehalogenation of these mono- and dichlorophenols was observed even when PCP was added to the culture medium as a possible inducer.

\section{DISCUSSION}

We isolated a member of a new bacterial species that is responsible for dechlorination of $\mathrm{PCP}$ to $3-\mathrm{CP}$ in a methanogenic consortium. On the basis of the results of a 16S rRNA sequence analysis, strain PCP-1 ${ }^{\mathrm{T}}$ is closely related to Desulfitobacterium dehalogenans JW/IU-DC1 (23). No other bacterial species are closely related to these two bacteria. Strain PCP-1 ${ }^{\mathrm{T}}$ and Desulfitobacterium dehalogenans share several characteris-

TABLE 1. Evolutionary distances between strain PCP $-1^{\mathrm{T}}$ and related taxa ${ }^{a}$

\begin{tabular}{|c|c|c|c|c|c|c|c|c|c|c|c|c|c|c|}
\hline \multirow{2}{*}{ Taxon } & \multicolumn{14}{|c|}{ Evolutionary distance from: } \\
\hline & 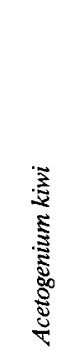 & 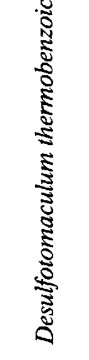 & 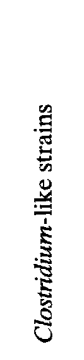 & 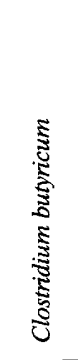 & 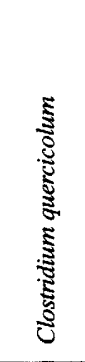 & 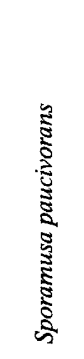 & 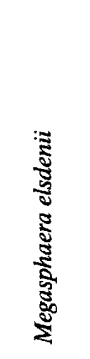 & 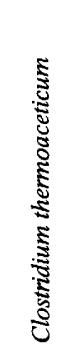 & 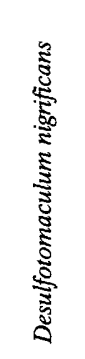 & 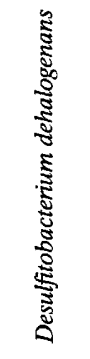 & 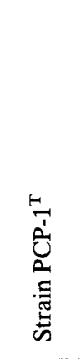 & 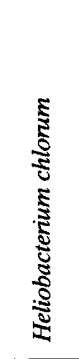 & 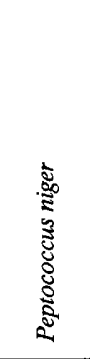 & 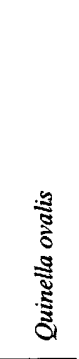 \\
\hline Desulfotomaculum thermobenzoicum & 0.186 & & & & & & & & & & & & & \\
\hline Clostridium-like strains & 0.230 & 0.227 & & & & & & & & & & & & \\
\hline Clostridium butyricum & 0.231 & 0.236 & 0.186 & & & & & & & & & & & \\
\hline Clostridium quercicolum & 0.219 & 0.210 & 0.206 & 0.251 & & & & & & & & & & \\
\hline Sporamusa paucivorans & 0.216 & 0.214 & 0.206 & 0.238 & 0.102 & & & & & & & & & \\
\hline Megasphaera elsdenii & 0.245 & 0.233 & 0.217 & 0.265 & 0.159 & 0.171 & & & & & & & & \\
\hline Clostridium thermoaceticum & 0.143 & 0.135 & 0.205 & 0.211 & 0.202 & 0.217 & 0.211 & & & & & & & \\
\hline Desulfotomaculum nigrificans & 0.198 & 0.143 & 0.212 & 0.209 & 0.203 & 0.222 & 0.211 & 0.166 & & & & & & \\
\hline Desulfitobacterium dehalogenans & 0.196 & 0.175 & 0.187 & 0.198 & 0.189 & 0.198 & 0.218 & 0.163 & 0.161 & & & & & \\
\hline Strain PCP-1 ${ }^{\mathrm{T}}$ & 0.231 & 0.231 & 0.192 & 0.209 & 0.194 & 0.193 & 0.231 & 0.174 & 0.178 & 0.032 & & & & \\
\hline Heliobacterium chlorum & 0.207 & 0.198 & 0.197 & 0.215 & 0.187 & 0.201 & 0.234 & 0.174 & 0.163 & 0.138 & 0.154 & & & \\
\hline Peptococcus niger & 0.238 & 0.226 & 0.237 & 0.235 & 0.236 & 0.235 & 0.232 & 0.196 & 0.201 & 0.198 & 0.216 & 0.220 & & \\
\hline Quinella ovalis & 0.231 & 0.224 & 0.241 & 0.246 & 0.175 & 0.196 & 0.212 & 0.227 & 0.229 & 0.226 & 0.226 & 0.199 & 0.252 & \\
\hline Escherichia coli & 0.289 & 0.300 & 0.278 & 0.267 & 0.333 & 0.331 & 0.313 & 0.281 & 0.303 & 0.279 & 0.289 & 0.283 & 0.310 & 0.326 \\
\hline
\end{tabular}

${ }^{a}$ The 1,421 unambiguously alignable nucleotide sites in the 15 sequences were used for pairwise comparisons in which the DNADIST program was used with the Kimura two-parameter option (13). 


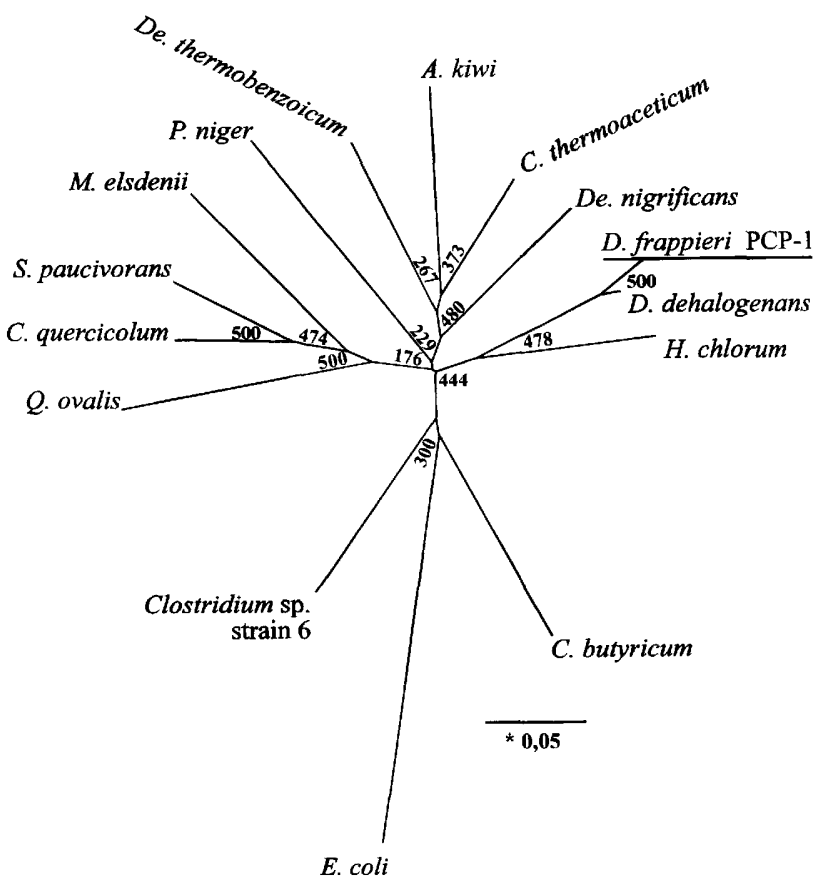

FIG. 4. Phylogenetic tree based on 16 S ribosomal DNA sequences of strain PCP-1 ${ }^{\mathrm{T}}$ and related species. The organisms whose sequences were used for comparison (GenBank accession numbers are in parentheses) were Desulfito bacterium frappieri PCP-1 ${ }^{\mathrm{T}}$ (U40078), Acetogenium kiwi (L09160), Clostridium butyricum (X68176), Clostridium quercicolum (M59110), Clostridium thermoaceticum (M59121), Desulfitobacterium dehalogenans (L28946), Desulfotomaculum nigrificans (X62176), Desulfotomaculum thermobenzoicum (M59121), Escherichia coli (J01695), Heliobacterium chlonum (M11212), Megasphaera elsdenii (L15628), Peptococcus niger (X55797), Quinella ovalis (M62701), Sporamusa paucivorans (M59117), and the phenol-transforming organism Clostridium sp. strain 6 (U27710), which was recently described by $\mathrm{Li}$ et al. (14). The tree was derived by using the FITCH program of the PHYLIP package (version 3.5), the distances in Table 1 , and the $E$. coli $16 \mathrm{~S}$ ribosomal gene as an outgroup. A bootstrap analysis of the same sequences was performed by using the SEOBOOT program and 500 replicates. The distances were calculated from each replicate with the DNADIST program by using the Kimura two-parameter option. The FITCH program was used to derive the best tree for each replicate. The CONSENSE program was used to derive the consensus tree. A total of 500 replicates were examined in the bootstrap analysis, and the numbers at the forks indicate how many times a species or a group of species originated at each fork. Bar $=0.05$ nucleotide substitution per site.

tics. They are both rod-shaped bacteria that are asaccharolytic and grow on media containing pyruvate and $0.1 \%$ yeast extract. Both organisms can use sulfite, thiosulfate, or nitrate, but not sulfate, as an inorganic electron acceptor. They are gram positive, although PCP- ${ }^{\mathrm{T}}$ stained gram negative. The $\mathrm{G}+\mathrm{C}$ contents of their genomic DNAs are similar $\left(46 \mathrm{~mol} \%\right.$ for PCP- $1^{\mathrm{T}}$ and $45 \mathrm{~mol} \%$ for Desulfitobacterium dehalogenans). Finally, they can reductively dehalogenate several chlorophenols. However, Desulfitobacterium dehalogenans can dehalogenate only chlorophenols with chlorines in ortho positions, whereas strain PCP $-1^{\mathrm{T}}$ is not limited to dehalogenation at this position.

There are several differences between the two species. PCP-1 $^{\mathrm{T}}$ forms spores, does not have flagella, and grows on $1.5 \%$ (wt/vol) agar plates. Desulfitobacterium dehalogenans apparently does not form spores, has flagella, and grows on solid media containing 0.6 to $0.9 \%$ agar but not in the presence of higher agar concentrations. The $16 \mathrm{~S}$ rRNA gene sequences of these organisms exhibited $95 \%$ homology, and there was a 128-nucleotide insertion that was unique to PCP-1 ${ }^{\mathrm{T}}$. These results suggest that PCP $-1^{\mathrm{T}}$ is a member of a species that is distinct from Desulfitobacterium dehalogenans. However, the

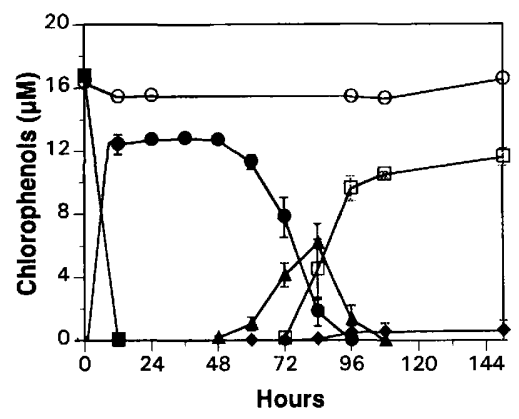

FIG. 5. Dechlorination of PCP by strain PCP $-1^{\mathrm{T}}$ in medium containing 20 $\mathrm{mM}$ pyruvate and $0.02 \%$ yeast extract. Symbols: $\mathrm{Q}$, PCP; $, 3,4,5$-trichlorophenol; $\boldsymbol{\Lambda}$, 3,5-dichlorophenol; $\diamond$, 3,4-dichlorophenol; $\square$, 3-CP; O, PCP (autoclaved culture). Data are means from triplicate determinations.

similarities between the two bacteria suggest that PCP-1 ${ }^{\mathrm{T}}$ belongs to the recently proposed genus Desulfitobacterium.

Strain PCP $-1^{\mathbf{T}}$ is the first anaerobic microorganism isolated that can dechlorinate PCP to 3-CP. PCP and the tetrachlorophenols are first dechlorinated at the ortho positions, then dechlorinated at the para positions, and then dechlorinated at the meta positions. Also, para dechlorination occurs only if chlorine residues are present in both meta positions. Other anaerobic microorganisms, including Desulfitobacterium dehalogenans JW/IU-DC1 $(22,23)$, strain DCB-2 (16), and the recently described organism strain XZ-1 (24), can generally dechlorinate only at ortho positions. Strain DCB-2 can remove a meta-substituted chlorine only from 3,5-dichlorophenol. However, Desulfomonile tiedjei DCB-1 meta dehalogenates a variety of substituted halobenzoates (9) and chlorophenols (18). Desulfitobacterium dehalogenans can remove the halogen at the ortho position when the para position is substituted, as it is in chlorinated $p$-hydroxyphenylacetate, $p$-hydroxybenzoates, $p$-nitrophenols, and $p$-cresols (22).

The kinetics of dechlorination of PCP by strain PCP $-1^{\mathrm{T}}$ revealed that $\mathrm{PCP}$ was rapidly dechlorinated to 3,4,5-trichlo-

TABLE 2. Transformation of chlorophenols by strain PCP-1 ${ }^{\mathrm{T}}$

\begin{tabular}{lll}
\hline \multicolumn{1}{c}{ Substrate $^{a}$} & \multicolumn{1}{c}{ Product(s) $^{a}$} & $\begin{array}{c}\text { Position of }^{a} \\
\text { dechlorination }^{b}\end{array}$ \\
\hline 2,3,4,5-TeCP & 3,4,5-TCP $\rightarrow$ 3,5-DCP $\rightarrow$ 3-CP & $o, p, m$ \\
2,3,5,6-TeCP & 2,3,5-TCP $\rightarrow$ 3,5-DCP $\rightarrow$ 3-CP & $o, o, m$ \\
2,3,4-TCP & 3,4-DCP & $o$ \\
2,3,5-TCP & 2,5-DCP & $m$ \\
2,3,6-TCP & 2,5-DCP & $o$ \\
2,4,5-TCP & 3,4-DCP & $o$ \\
2,4,6-TCP & 2,4-DCP $\rightarrow$ 4-CP & $o, o$ \\
3,4,5-TCP & 3,5-DCP $\rightarrow$ 3-CP & $p, m$ \\
2,6-DCP & 2-CP & $o$ \\
2,4-DCP & 4-CP & $o$ \\
3,5-DCP & 3-CP & \\
2,3-DCP & No dechlorination & \\
2,5-DCP & No dechlorination & \\
3,4-DCP & No dechlorination & \\
2-CP & No dechlorination & \\
3-CP & No dechlorination & \\
4-CP & No dechlorination & \\
\end{tabular}

${ }^{a}$ Abbreviations: TeCP, tetrachlorophenol; TCP, trichlorophenol; DCP, dichlorophenol; $\mathrm{CP}$, chlorophenol.

${ }^{\circ} o$, ortho; $p$, para; $m$, meta.

${ }^{c}$ No dechlorination occurred in the presence or in the absence of $3 \mathrm{mg}$ of PCP per liter as an inducer. 
rophenol and that there was a $36-\mathrm{h}$ lag period before this compound was dechlorinated to 3,5-dichlorophenol and 3-CP. This result suggests that two different enzyme systems are involved in PCP dechlorination. The first system dechlorinates PCP rapidly and dechlorinates 2,3,4,5-tetrachlorophenol only at the ortho position to generate 3,4,5-trichlorophenol, while the second system dechlorinates 3,4,5-trichlorophenol at the meta and para positions to generate 3-CP. PCP and tetrachlorophenols may act as inducers of the ortho dechlorination, and 3,4,5-trichlorophenol may act as an inducer of dechlorination in the para and meta positions. For 3,4,5-trichlorophenol, a 36-h lag period is probably needed for the bacterial cells to induce and generate the dechlorination enzymes, whereas for PCP no lag period is needed. This hypothesis for induction of ortho and meta-para dechlorinations could explain the differences observed with 2,3,5-trichlorophenol dechlorination. 2,3,5,6-Tetrachlorophenol induced ortho dechlorination and the intermediate 2,3,5-trichlorophenol was dechlorinated to 3,5-dichlorophenol. However, when 2,3,5-trichlorophenol was tested separately, meta dechlorination was induced, and this chlorophenol was dechlorinated to 2,5-dichlorophenol. This hypothesis is currently being tested.

To our knowledge, PCP-1 $1^{\mathrm{T}}$ is the first anaerobic bacterium that is able to reductively dechlorinate PCP and different chlorophenols at ortho, meta, and para positions. Experiments are now being carried out to optimize the conditions for culturing $\mathrm{PCP}-1^{\mathrm{T}}$ and to evaluate the potential for transforming other classes of halogenated compounds.

\section{ACKNOWLEDGMENTS}

We thank Rita Alary and Francine Turcotte for excellent technical assistance.

This work was supported by Hydro-Québec, in part by Fonds pour la Formation de Chercheurs et l'Aide à la Recherche and Centre Québécois de Valorisation de la Biomasse, and by grant STR0166954 from the Natural Sciences and Engineering Research Council of Canada.

\section{REFERENCES}

1. Alain, R., F. Nadon, C. Séguin, P. Payment, and M. Trudel. 1987. Rapid virus subunit visualization of samples on electron microscope grids. J. Virol. Methods 16:209-216.

2. Boyd, S. S., D. R. Shelton, D. Berry, and J. M. Tiedje. 1983. Anaerobic biodegradation of phenolic compounds in digested sludge. Appl. Environ. Microbiol. 46:50-54.

3. Brosius, J., M. L. Palmer, P. J. Kennedy, and H. F. Noller. 1978. Complete nucleotide sequence of a $16 \mathrm{~S}$ ribosomal RNA gene from Escherichia coli. Proc. Natl. Acad. Sci. USA 75:4801-4805.

4. Bruce, K. D., W. D. Hiorns, J. L. Hobman, A. M. Osborn, P. Strike, and D. A Ritchie. 1992. Amplification of DNA from native populations of soil bacteria by using polymerase chain reaction. Appl. Environ. Microbiol. 58:3414-3416.

5. Cole, J. R., A. L. Cascarelli, W. W. Mohn, and J. M. Tiedje. 1994. Isolation and characterization of a novel bacterium growing via reductive dehaloge- nation of 2-chlorophenol. Appl. Environ. Microbiol. 60:3536-3542.

6. Collins, M. D., P. A. Lawson, A. Willems, J. J. Cordoba, J. FernandezGarayzabal, P. Garcia, J. Cai, H. Hippe, and J. A. Farrow. 1994. The phylogeny of the genus Clostridium: proposal of five new genera and eleven new species combinations. Int. J. Syst. Bacteriol. 44:812-826.

7. DeWeerd, K. A., L. Mandelco, R. S. Tanner, C. R. Woese, and J. M. Suflita. 1990. Desulfomonile tiedjei gen. nov. and sp. nov., a novel anaerobic, dehalogenating, sulfate reducing bacterium. Arch. Microbiol. 154:23-30.

8. Dolfing, J. 1990. Reductive dechlorination of 3-chlorobenzoate is coupled to ATP production and growth in an anaerobic bacterium, strain DCB-1. Arch. Microbiol. 153:264-266.

9. Dolfing, J., and J. M. Tiedje. 1991. Influence of substituents on reductive dehalogenation of 3-chlorobenzoate analogs. Appl. Environ. Microbiol. 57: $820-824$.

10. Felsenstein, J. 1989. PHYLIP: phylogeny inference package (version 3.2). Cladistics 5:164-166.

11. Juteau, P., R. Beaudet, G. McSween, F. Lépine, and J.-G. Bisaillon. 1995 Study of the reductive dechlorination of pentachlorophenol by a methanogenic consortium. Can. J. Microbiol. 46:862-868.

12. Juteau, P., R. Beaudet, G. McSween, F. Lépine, S. Milot, and J. G. Bisaillon. 1995. Anaerobic biodegradation of pentachlorophenol by a methanogenic consortium. Appl. Microbiol. Biotechnol. 44:218-224.

13. Kimura, M. 1980 . A simple model for estimating evolutionary rates of base substitutions through comparative studies of nucleotide sequences. J. Mol. Evol. 16:111-120.

14. Li, T., J. G. Bisaillon, R. Villemur, L. Létourneau, K. Bernard, F. Lépine, and R. Beaudet. 1996. Isolation and characterization of a new bacterium carboxylating phenol to benzoic acid under anaerobic conditions. J. Bacteriol. 178:2551-2558.

15. Linkfield, T. G., and J. M. Tiedje. 1990. Characterization of the requirements and substrates for reductive dehalogenation by strain DCB-1. J. Ind. Microbiol. 5:9-16.

16. Madsen, T., and D. Licht. 1992. Isolation and characterization of an anaerobic chlorophenol-transforming bacterium. Appl. Environ. Microbiol. 58: 2874-2878.

17. Mesbah, M., U. Premachandran, and W. B. Whitman. 1989. Precise measurement of the $\mathrm{G}+\mathrm{C}$ content of deoxyribonucleic acid by high-performance liquid chromatography. Int. J. Syst. Bacteriol. 39:159-167.

18. Mohn, W. W., and K. J. Kennedy. 1992. Reductive dehalogenation of chlorophenols by Desulfomonile tiedjei DCB-1. Appl. Environ. Microbiol. 58: 1367-1370.

19. Mohn, W. W., and J. M. Tiedje. 1991. Evidence for chemiosmotic coupling of reductive dehalogenation and ATP synthesis in Desulfomonile tiedjei. Arch. Microbiol. 157:1-6.

20. Neefs, J. M., Y. Van de Peer, L. Hendriks, and R. De Watcher. 1990 Compilation of small ribosomal subunit RNA sequences. Nucleic Acids Res. 18:2237-2317.

21. Sanger, F., S. Nicklen, and A. R. Coulson. 1977. DNA sequencing with chain-terminating inhibitors. Proc. Natl. Acad. Sci. USA 74:5463-5467.

22. Utkin, I., D. D. Dalton, and J. Wiegel. 1995. Specificity of reductive dehalogenation of substituted ortho-chlorophenols by Desulfitobacterium dehalogenans JW/IU-DC1. Appl. Environ. Microbiol. 61:346-351.

23. Utkin, I., C. Woese, and J. Wiegel. 1994. Isolation and characterization of Desulfitobacterium dehalogenans gen. nov., sp. nov., an anaerobic bacterium which reductively dechlorinates chlorophenolic compounds. Int. J. Syst. Bacteriol. 44:612-619.

24. Zhang, X., J. Jones, and J. Rogers. 1995. Isolation and partial characterization of an anaerobic dehalogenating microorganism, abstr. Q-11, p. 401. In Abstracts of the 95th General Meeting of the American Society for Microbiology 1995. American Society for Microbiology, Washington, D.C.

25. Zuker, M., and P. Stiegler. 1981. Optimal computer folding of large RNA sequences using thermodynamics and auxiliary information. Nucleic Acids Res. 9:133-148. 